\title{
Genetic Transformation in Encapsulated Clinical Isolates of Haemophilus influenzae Type b
}

\author{
By PRADEEP ROWJI, ROSA GROMKOVA* AND \\ HENDRIK KOORNHOF
}

Emergent Pathogen Research Unit of the South African Medical Research Council, School of Pathology of the University of the Witwatersrand and the South African Institute for Medical Research, 7 York Road, Parktown, Johannesburg 2193, Republic of South Africa

(Received 23 February 1989; revised 5 June 1989; accepted 7 July 1989)

\begin{abstract}
Haemophilus influenzae type $\mathrm{b}$ strains isolated from children with meningitis, septicaemia and pharyngitis were studied for their ability to undergo genetic transformation by two chromosomal markers, streptomycin resistance and nalidixic acid resistance. Fifty-eight percent of the strains were non-transformable while the remaining $42 \%$ showed considerable strain variation with regard to their transformation frequencies, which ranged from $8 \times 10^{-4}$ to $1 \times 10^{-6}$. The effect of type b capsule on competence development and transformation activity was studied by comparing encapsulated strains with their non-encapsulated variants. Type $b$ capsule did not inhibit either competence development or transforming efficiency. The lack of transformability in the majority of strains was not due to the presence of a capsule.
\end{abstract}

\section{INTRODUCTION}

Genetic transformation in Haemophilus influenzae was first described by Alexander \& Leidy (1950). Since then this system has been one of the models used for studying the mechanism of DNA transformation (Smith \& Danner, 1981; Goodgal, 1982). Other genera that possess efficient, genetically determined mechanisms for DNA transformation include Streptococcus, Bacillus and Neisseria. Recent investigations have revealed many interesting features of the transformation process in $H$. influenzae at both the cellular and molecular level (Kahn \& Smith, 1984). Despite the significant progress in this field very little is known about the biological role of transformation. Most studies on DNA transformation in Haemophilus have been done with a single highly transformable non-encapsulated avirulent strain, $\mathrm{Rd}$, derived from $H$. influenzae type d (Alexander \& Leidy, 1951). Transformation assays have usually been performed under strictly defined experimental conditions. It is difficult to imagine that similar conditions would occur in nature. $H$. influenzae strains isolated from patients with meningitis and sepsis are usually encapsulated (Turk, 1981). Of the six capsular serological types (a through f), strains that possess the type $b$ capsule have been found to be the major cause of systemic infections in children. No detailed information on the transformability of an extended number of encapsulated clinical isolates of $H$. influenzae is available, neither has the effect of type b capsule on DNA transformation been studied. Furthermore, little is known about the possible role of DNA transformation in the transfer of antimicrobial resistance or in the pathogenesis of infections caused by this organism. In an attempt to answer some of the above questions, we have initiated studies on the ability of clinical isolates of $H$. influenzae to undergo genetic transformation. In addition, we have compared transformation activity in both encapsulated and non-encapsulated strains and studied the relationship between transformability and other biological features such as drug resistance, biotype and site of infection. 


\section{METHODS}

Bacterial strains and growth. $H$. influenzae strains were isolated from paediatric patients at Baragwanath Hospital, Johannesburg, and the King Edward VIII Hospital, Durban. Fourteen strains were recovered from cerebro-spinal fluid, seven from blood cultures and 10 from throat specimens.

$H$. influenzae Rd was provided by G. Leidy, USA (Alexander \& Leidy, 1951). Antibiotic-resistant strains used as donors in DNA transformation were obtained by selecting spontaneous mutants on antibiotic-containing plates.

H. influenzae strains were grown in Brain Heart Infusion (BHI) broth and BHI agar (Becton Dickinson) supplemented with $10 \mu \mathrm{g}$ haemin $\mathrm{ml}^{-1}$ and $2 \mu \mathrm{g} \mathrm{NAD} \mathrm{ml}^{-1}$ (both from Sigma). Leventhal agar (Catlin, 1970) was used for plating cultures for colony iridescence (Pittman, 1931; Catlin et al., 1972). Mueller-Hinton agar (Oxoid) supplemented with $2 \%(\mathrm{w} / \mathrm{v})$ haemoglobin (Difco) and $2 \mu \mathrm{g} \mathrm{NAD} \mathrm{ml-1}$ was used as growth medium for determination of minimal inhibitory concentrations (MICs) of antibiotics.

Serotyping. Capsular serotypes were determined by slide agglutination with six (a through f) type-specific antisera (Wellcome Diagnostics). Presence of capsule was further confirmed by testing for colony iridescence by stereomicroscopy with obliquely transmitted light (Pittman, 1931). Non-encapsulated mutants were isolated by passage in supplemented BHI broth followed by plating on BHI and Levinthal agar. Only colonies that had lost both iridescence and agglutinability were considered to be true non-encapsulated mutants.

DNA transformation. Purified DNA was prepared by the chloroform/octanol method (Goodgal, 1968). Isogenic DNA preparations were used as donors in the transformation experiments. Competence was induced by the static aerobic procedure (Gromkova et al., 1989). This technique is similar to that described for the induction of competence in Haemophilus parainfluenzae (Gromkova \& Goodgal, 1979). Overnight cultures grown in BHI broth were diluted $1: 25$ into supplemented BHI broth. Samples $(10 \mathrm{ml})$ were incubated in $90 \mathrm{~mm}$ plastic Petri dishes at $37^{\circ} \mathrm{C}$ without shaking to early stationary phase $\left(\mathrm{OD}_{650} 0 \cdot 6\right)$. For the transformation assay, $0 \cdot 1 \mathrm{ml}$ DNA at saturating concentration $\left(3 \mu \mathrm{g} \mathrm{ml}^{-1}\right)$, was added to $0.8 \mathrm{ml} \mathrm{BHI}$ broth supplemented with $1 \mathrm{mM}-\mathrm{MgSO}_{4}$. After the addition of $0.1 \mathrm{ml}$ competent cells, the mixture was incubated for $30 \mathrm{~min}$ at $35^{\circ} \mathrm{C}$ without shaking and then pancreatic DNAase added to $10 \mu \mathrm{g} \mathrm{ml}^{-1}$. After a further $10 \mathrm{~min}$ at $35^{\circ} \mathrm{C}$ the mixture was diluted and each dilution was plated in triplicate for transformants by using an overlay method. Selected clinical isolates were tested for transforming activity by the M IV procedure (Herriott et al., 1970).

Biotype determination. Strains were asssigned to one of six biotypes (Kilian, 1976) on the basis of catalase, oxidase, nitrate reductase, indole, urease and ornithine decarboxylase production.

Determination of MIC. MICs of ampicillin (Amp), chloramphenicol (Cam), tetracycline (Tet), streptomycin (Str), nalidixic acid (Nal), erythromycin (Ery) and novobiocin (Nov) were determined according to the standard method approved by the National Committee for Clinical Laboratory Standards (NCCLS) (Thornsberry, et al.,1985).

$\beta$-Lactamase production. The nitrocephin method was used to demonstrate the elaboration of $\beta$-lactamase (O'Callaghan et al., 1972).

\section{RESULTS}

\section{Transformability of encapsulated isolates}

All the clinical isolates agglutinated strongly with type $b$ antiserum and none crossagglutinated with the remaining five type-specific antisera. They all produced opaque and iridescent colonies, characteristic of encapsulated $H$. influenzae. When the strains were grown by the static aerobic procedure used for competence development, all expressed their capsular antigen, as confirmed by the agglutination test. The transformation efficiencies of the clinical isolates were examined by transforming with isogenic DNA from streptomycin-resistant (Str $\left.{ }^{r}\right)$ and nalidixic-acid-resistant $\left(\mathrm{Nal}^{\mathrm{r}}\right)$ mutants (Table 1). Eighteen out of 31 clinical isolates $(58 \%)$ were non-transformable (transformation frequency of $<10^{-8}$ ), while 13 strains were able to undergo genetic transformation at frequencies ranging from $8 \times 10^{-4}$ to $3 \times 10^{-6}$ for the $\mathrm{Nal}^{\mathrm{r}}$ marker and $6 \times 10^{-4}$ to $1 \times 10^{-6}$ for the $\operatorname{Str}^{r}$ marker (Table 1). Each experiment was repeated three times with different batches of competent cells. Differences in transformation frequencies were not greater than a factor of two to three. Using the same preparation of competent cells, transformation efficiency to streptomycin resistance was about two- to threefold lower than to nalidixic acid resistance. A similar ratio between these two markers was found in $H$. influenzae Rd.

Because of the relatively low level of competence in encapsulated $H$. influenzae type b strains, we attempted to determine whether competence occurred only in occasional cells that had either lost their capsules or contained defective capsules. Transformation frequencies of the wild-type clinical isolates were compared with those of transformants after one round of transformation. 
Table 1. Transformation of $H$. influenzae type $b$ by isogenic chromosomal DNA

Competent cells at a concentration of approximately $2 \times 10^{8}$ c.f.u. $\mathrm{ml}^{-1}$ were used in the transformation mixture. Transformation frequency was determined by dividing the number of transformants by the number of c.f.u. Purified isogenic DNA prepared from a $\operatorname{Str}^{r} \mathrm{Nal}^{\mathrm{r}}$ mutant obtained from each clinical isolate was used as donor. The concentrations of nalidixic acid and streptomycin used for selection of transformants were $3 \mu \mathrm{g} \mathrm{ml}^{-1}$ and $200 \mu \mathrm{g} \mathrm{m}^{-1}$ respectively.

$\begin{array}{lcc}\begin{array}{c}\text { Recipient } \\ \text { strain }\end{array} & \overbrace{\mathrm{Nal}^{\mathrm{r}}}^{\text {Frequency of transformation }} \\ 35910 & 8 \times 10^{-4} & 6 \times 10^{-4} \\ 126814 & 2 \times 10^{-4} & 5 \times 10^{-5} \\ 168 & 3 \times 10^{-5} & 1 \times 10^{-5} \\ 5 & 2 \times 10^{-5} & 8 \times 10^{-6} \\ 122155 & 5 \times 10^{-5} & 2 \times 10^{-5} \\ 1226 & 1 \times 10^{-4} & 6 \times 10^{-5} \\ 128011 & 4 \times 10^{-4} & 3 \times 10^{-4} \\ 37710 & 8 \times 10^{-5} & 3 \times 10^{-5} \\ 12 & 3 \times 10^{-4} & 8 \times 10^{-5} \\ 10674 & 8 \times 10^{-4} & 5 \times 10^{-5} \\ 16412 & 3 \times 10^{-5} & 2 \times 10^{-5} \\ 64 & 3 \times 10^{-6} & 1 \times 10^{-6} \\ 145 & 7 \times 10^{-4} & 3 \times 10^{-4}\end{array}$

Table 2. Transformation of wild-type $H$. influenzae type $b$ and streptomycin-resistant transformants to nalidixic acid resistance

$\begin{array}{lcc}\begin{array}{c}\text { Recipient } \\ \text { strain }\end{array} & \overbrace{\text { Wild-type }}^{\text {Trequency of transformation* }}{ }^{*} \\ 35910 & 4 \times 10^{-4} & 7 \times 10^{-4} \\ 12684 & 7 \times 10^{-5} & 4 \times 10^{-5} \\ 168 & 1 \times 10^{-4} & 3 \times 10^{-4} \\ 5 & 8 \times 10^{-5} & 1 \times 10^{-5} \\ 122155 & 5 \times 10^{-5} & 2 \times 10^{-4} \\ 12226 & 9 \times 10^{-5} & 2 \times 10^{-4} \\ 128011 & 3 \times 10^{-5} & 3 \times 10^{-5} \\ 37710 & 2 \times 10^{-5} & 7 \times 10^{-5} \\ 12 & 6 \times 10^{-4} & 2 \times 10^{-4} \\ 19674 & 2 \times 10^{-4} & 7 \times 10^{-4} \\ 16412 & 4 \times 10^{-5} & 4 \times 10^{-5} \\ 64 & 2 \times 10^{-6} & 3 \times 10^{-6} \\ 145 & 4 \times 10^{-4} & 9 \times 10^{-4}\end{array}$

* See legend of Table 1 .

If transformation only occurred in capsule-deficient variants, an increase in transformation frequency would be expected during a second round of transformation. Thus, $\operatorname{Str}^{\mathrm{r}} \operatorname{transformants}^{\mathrm{s}}$ were tested for transformation efficiencies using the $\mathrm{Nal}^{\mathrm{r}}$ marker. The corresponding wild-type isolates were used as controls. Transformation frequencies to $\mathrm{Nal}^{\mathrm{r}}$ were similar for wild-type isolates and their $\operatorname{Str}^{r}$ transformants (Table 2), indicating that the two cell types possess equal potential to become competent. The presence of capsule in the transformants was confirmed by a positive agglutination test with type $b$ antiserum and by colony iridescence.

The donor activity of the DNA preparations obtained from five transformable and five nontransformable clinical isolates of $H$. influenzae was tested by using the highly transformable strain of $H$. influenzae $\mathrm{Rd}$ as a recipient. All DNA preparations were efficient donors for both the $\operatorname{Str}^{\mathrm{r}}$ and $\mathrm{Nal}^{\mathrm{r}}$ markers (Table 3). This suggested that the lack of transforming ability in some clinical isolates was not due to poor donor activity. 
Table 3. Donor activity of DNA from clinical isolates of $H$. influenzae type $b$ in $H$. influenzae $R d$ recipient cells

\begin{tabular}{|c|c|c|c|}
\hline \multirow{2}{*}{$\begin{array}{c}\text { Source of } \\
\text { donor DNA }\end{array}$} & \multirow[b]{2}{*}{ Transformable } & \multicolumn{2}{|c|}{ Frequency of transformation } \\
\hline & & $\mathrm{Nal}^{\mathbf{r}}$ & $\operatorname{Str}^{r}$ \\
\hline 35910 & Yes & $4 \times 10^{-3}$ & $2 \times 10^{-3}$ \\
\hline 126814 & Yes & $6 \times 10^{-3}$ & $4 \times 10^{-3}$ \\
\hline 5 & Yes & $5 \times 10^{-3}$ & $3 \times 10^{-3}$ \\
\hline 122155 & Yes & $3 \times 10^{-3}$ & $1 \times 10^{-3}$ \\
\hline 128011 & Yes & $3 \times 10^{-3}$ & $1 \times 10^{-3}$ \\
\hline 24576 & No & $4 \times 10^{-3}$ & $2 \times 10^{-3}$ \\
\hline 122178 & No & $5 \times 10^{-3}$ & $3 \times 10^{-3}$ \\
\hline 122160 & No & $3 \times 10^{-3}$ & $2 \times 10^{-3}$ \\
\hline 77077 & No & $4 \times 10^{-3}$ & $3 \times 10^{-3}$ \\
\hline 15831 & No & $5 \times 10^{-3}$ & $2 \times 10^{-3}$ \\
\hline $\mathbf{R d}$ & Yes & $8 \times 10^{-3}$ & $5 \times 10^{-3}$ \\
\hline
\end{tabular}

Table 4. Comparison of transformation frequencies between encapsulated $H$. influenzae type $b$ isolates and their non-encapsulated variants

$\begin{array}{lcc}\begin{array}{c}\text { Recipient } \\ \text { strain }\end{array} & \overbrace{\text { Encapsulated }}^{\text {Frequency of transformation to Str }{ }^{\mathrm{r} *}} \\ 12 & \begin{array}{c}\text { Non-encapsulated } \\ 2 \times 10^{-4}\end{array} & 2 \times 10^{-4} \\ 24576 & <10^{-8} & <10^{-8} \\ 5 & 1 \times 10^{-5} & 8 \times 10^{-6} \\ 71781 & <10^{-8} & <10^{-8} \\ 12684 & 5 \times 10^{-5} & 5 \times 10^{-5} \\ 122178 & <10^{-8} & <10^{-8} \\ 35910 & 3 \times 10^{-4} & 4 \times 10^{-4} \\ & \text { * See legend of Table } 1 .\end{array}$

Effect of type b capsule on DNA transformation

To study the effect of type $b$ capsule on DNA transformation, non-encapsulated variants were selected from encapsulated transformable and non-transformable clinical isolates. Transformation frequencies of these variants were compared with those of the corresponding encapsulated strains. No significant differences in the efficiencies of transformation of encapsulated strains and their non-encapsulated variants were found (Table 4). This suggested that the presence of type b capsule did not inhibit DNA transformation. Non-encapsulated variants derived from encapsulated non-transformable strains remained non-transformable, indicating that the presence of capsule was not responsible for the lack of transformation.

\section{Development of competence in $H$. influenzae type $b$}

Lack of transformability in a large number of clinical isolates of $H$. influenzae type b using static aerobic conditions of growth suggested that competence may not occur during the early stationary phase of growth but rather at some other stage in the growth cycle. In order to test this hypothesis, the kinetics of competence development of two non-transformable and two transformable encapsulated clinical isolates of $H$. influenzae type $\mathrm{b}$ and their non-encapsulated variants were tested. No detectable levels of competence were found at any stage in the growth cycle of the two non-transformable clinical isolates (data not presented). This suggested that the strains were probably naturally incompetent. Fig. 1 presents the kinetics of competence 


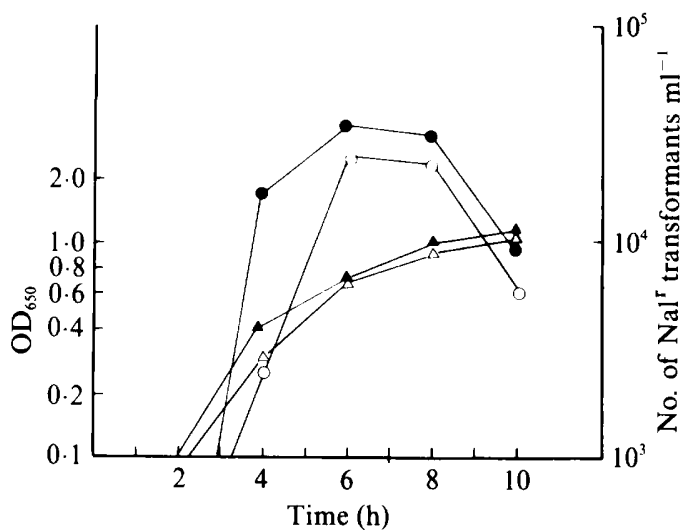

Fig. 1. Kinetics of competence development and cell growth of encapsulated $H$. influenzae 12 $(\Delta, \bullet)$ and its non-encapsulated variant $(\triangle, O)$. Cells were grown without shaking and sampled at $1 \mathrm{~h}$ intervals for $\operatorname{OD}_{650}(\Delta, \triangle)$ and transforming activity $(\bullet, O)$. Only values of $2 \mathrm{~h}$ intervals are presented.

development and cell growth of the transformable encapsulated $H$. influenzae strain 12 and its non-encapsulated variant. The kinetics of competence of these strains followed a similar profile. The peak in competence was reached at the early stationary phase. This was also true for a second transformable encapsulated strain, 35910, and its non-encapsulated variant (data not presented). It was concluded that the type b capsule does not inhibit the development of competence in $H$. influenzae.

\section{Induction of competence by the MIV procedure}

The M IV procedure has been reported to be the most efficient procedure for induction of competence of the non-encapsulated strain $\mathrm{Rd}$ of $H$. influenzae (Herriott et al., 1970). However, this method was not suitable for testing the ability of encapsulated clinical isolates to undergo genetic transformation or for studying the effect of the capsule on the transformation because it interferes with capsule synthesis. Since we were able to demonstrate that the presence of a capsule does not inhibit transformation, it was of interest to investigate whether clinical isolates that could not be induced for competence by the static aerobic procedures were able to develop competence in the defined M IV medium. Another point of interest was to compare the efficiency of transformation of competent cells induced by the static aerobic procedure with that of cells induced by the M IV method. Five non-transformable and three transformable isolates were tested for transformation efficiencies after induction of competence by the M IV method. We were not able to establish detectable levels of competence with the latter method in the strains that were previously found to be non-transformable by the static aerobic procedure. The three transformable strains showed efficiencies of transformation that were two to three times lower than those obtained in the cells induced by the static aerobic procedure when $\operatorname{Str}^{\mathrm{r}}$ and Nal${ }^{\mathrm{r}}$ transformants were selected. These results were reproducible using three different batches of competent cells.

\section{Relationship between transformability and other biological features}

If DNA transformation is an important mechanism for the spread of drug resistance in nature, it might be expected that antibiotic-resistant strains would tend to be transformable. We designed an experiment to determine possible correlations between the presence of drug resistance in clinical isolates and their ability to undergo transformation. In naturally occurring drug-resistant clinical isolates, genes that confer resistance to clinically relevant antimicrobial agents are usually plasmid linked. However, we have not yet determined the presence of plasmids in our strains and have not studied the transforming ability of the naturally occurring drug-resistance genes. Instead, we examined the ability of the clinical isolates to be transformed 
Table 5. Comparison of the number of drug-resistant and drug-sensitive isolates that are transformable

Pattern of
resistance*
Amp
Amp Cam
Amp Tet
Amp Cam Tet
Sensitive $\dagger$

Total no.
of strains
5
3
7
2
14

No.
transformable
2
1
2
0
8

No. non-transformable

* MICs of Amp, Cam and Tet were $>2 \mu \mathrm{g} \mathrm{ml}^{-1},>4 \mu \mathrm{g} \mathrm{ml}^{-1}$ and $>4 \mu \mathrm{g} \mathrm{ml}^{-1}$ respectively. All Amp strains produced $\beta$-lactamase. None of the strains was resistant to Str, Ery, Nal and Nov.

$\dagger$ The strains were tested for sensitivity to seven antibiotics (see Methods).

by two chromosomal markers ( $\operatorname{Str}^{\mathrm{r}}$ and $\mathrm{Nal}{ }^{\mathrm{r}}$ ). A correlation has previously been demonstrated in $H$. influenzae between competence development for transformation of chromosomal and plasmid markers respectively (Notani et al., 1981). Our results (Table 5) showed that of the 17 drug-resistant strains tested, only five were transformable, while of the 14 drug-sensitive strains, eight were able to undergo transformation. It is not clear whether the presence of drug resistance has an inhibitory effect on transformation, as was reported by Stuy (1979).

Unlike the situation in Europe and the United States, where biotype I predominates (van Alphen et al., 1987), most of our isolates belong to biotype II. Of the 31 isolates tested, six transformable and three non-transformable strains belonged to biotype I while six transformable and 12 non-transformable strains belonged to biotype II. Only four strains belonged to biotypes III and IV; one, a non-transformable strain, belonged to biotype IV and of the three biotype III isolates, two were non-transformable.

The ability of $H$. influenzae type b strains from patients with meningitis and bacteraemia to be transformed by chromosomal DNA was compared with that of strains from patients with pharyngitis. Of the 14 isolates from cerebro-spinal fluid, six were transformable, while two of seven blood cultures and three of 10 throat cultures were transformable. These observations are, however, too limited for valid conclusions to be drawn about a possible relationship between transformability and pathogenic potential.

\section{DISCUSSION}

Early studies on DNA transformation in $H$. influenzae provided evidence that nonencapsulated variants of type $d$ were the most efficient recipients in DNA transformation, followed by those of type $b$, e and $a$, while non-encapsulated variants of type $c$ and $f$ were nontransformable (Alexander et al., 1953). It was concluded that a correlation exists between frequency of transformation and serotype of origin. In contrast, we have found that encapsulated serotype $b$ isolates show significant differences in their transformation ability, ranging from an apparent lack of transformation to a transformation activity of $8 \times 10^{-4}$ to $1 \times 10^{-6}$. Considerable heterogeneity, based on outer-membrane protein and lipopolysaccharide gel profiles, occurs in strains of $\boldsymbol{H}$. influenzae type b encountered in different geographical regions (Tolan et al., 1986; van Alphen et al., 1987). It would be of interest to compare strains from different locations in order to ascertain whether they differ in their levels of competence as well as the ratio between transformable and non-transformable strains. Such studies should also be extended to include serotypes other than type b. The efficiency of transformation of $H$. influenzae $\mathrm{Rd}$ was 10 - to 100 -fold higher than that of type $\mathrm{b}$ isolates, when the static aerobic procedure for induction of competence was used. Since clinical isolates of $H$. influenzae type d were not available at the time, we were not able to examine whether type $d$ strains were characteristically more efficient in transformation or whether this was a property of individual strains. 
The finding that more than half of the $H$. influenzae type b strains were non-transformable cannot at present be explained. However, the possibility cannot be excluded that, in nature, transformation occurs by a pathway different from that observed in vitro. It seems unlikely that the lack of competence was due to the absence of some unknown factor(s) necessary for competence development in the media used. In support of this conclusion was the finding that non-transformable strains were not able to develop competence either by the static aerobic procedure or in the defined M IV medium. Although it is difficult to reproduce accurately conditions prevailing in the host, the static aerobic procedure seems to approximate better the natural environment in the upper respiratory tract than the procedure with the synthetic $\mathbf{M}$ IV medium.

The inability of some clinical isolates of $H$. influenzae type $\mathrm{b}$ to be transformed is probably not due to the effect of restriction enzymes. Although Haemophilus bacteria are known to be a rich source of such enzymes, previous studies have demonstrated that they do not play a role in the exclusion of bacterial transforming DNA in vivo (Gromkova \& Goodgal, 1977). In addition, isogenic DNA is usually protected against the action of restriction enzymes. However, an inhibitory effect on transformation by non-specific endodeoxyribonucleases cannot be excluded. Hoiseth et al. (1986) have recently shown that loss of encapsulation is related to recombination between two copies of an $18 \mathrm{~kb}$ tandem duplication. This finding may explain the relatively large number of non-transformable isolates recovered from clinical cases in this study since we were unable to obtain non-encapsulated variants from most of the nontransformable isolates, suggesting that they may be deficient in recombination.

The study of the relationship between the presence of capsule and transformability was one of the major objectives of this investigation. The type b capsule of $H$. influenzae is reported to consist of a polymer of ribosylribitol phosphate (Zamenhoff et al., 1953; Crisel et al., 1975). Recent studies on cellular changes that occur during the development of competence have provided evidence that competence is associated with the appearance of vesicles on the outer membrane (Kahn et al., 1979; Kahn \& Smith, 1984). These vesicles (called 'transformasomes') have been implicated in the uptake and transport of DNA during transformation (Kahn et al., 1983). We found that the capsule does not interfere with DNA transformation, suggesting that discontinuity of the capsule or some other property of the capsule allows DNA molecules to overcome the capsular barrier. A recent report on the effect of the capsule of Streptococcus pneumoniae on DNA transformation indicates that the capsule inhibits the release of competence factor and that transformation may only occur after the addition of an exogenous competence factor (Yother et al., 1986); the efficiency of transformation of encapsulated $S$. pneumoniae was about fourfold lower than in the corresponding non-encapsulated variants. In contrast, in $H$. influenzae type b, neither induction nor level of competence was affected by the presence of a capsule. The different effect of the capsule on DNA transformation in $S$. pneumoniae and $H$. influenzae type b may relate to differences in the mechanism of competence induction in the two systems or to the chemical composition of their capsules. However, a common feature of $S$. pneumoniae and $H$. influenzae type b transformation systems is that the presence of a capsule in clinical isolates is not responsible for their inability to transform. Furthermore, strain variation in transformability is characteristic of both systems (Bracco et al., 1957).

We wish to thank G. Leidy, C. Heney, Y. Coovadia, M. Khoosal and J. Summer for kindly providing us with bacterial strains.

\section{REFERENCES}

Alexander, H. E. \& Leidy, G. (1950). Transformation of type specificity of Haemophilus influenzae. Proceedings of the Society for Experimental Biology and Medicine 73, 485-487.

AleXANDER, H. E. \& LeIDY, G. (1951). Determination of inherited traits of Haemophilus influenzae by desoxyribonucleic acid fractions isolated from type specific cells. Journal of Experimental Medicine 93, 345-349.

AleXANDER, H. E., LeIDY, G. \& HAHN, E. (1953). Studies on the nature of Haemophilus influenzae cells susceptible to heritable changes by desoxyribonucleic acids. Journal of Experimental Medicine 99, 505-533. 
van Alphen, L., Geelen, L., Jonsdottir, K., TAKala, A. H., KaYhTY, H. \& ZANEN, H. C. (1987). Distinct geographic distribution of subtypes of Haemophilus influenzae type b in Western Europe. Journal of Infectious Diseases 156, 216-218.

Bracco, R. M., Kraus, M. R., Roe, A. S. \& MACLEOD, C. M. (1957). Transformation reactions between pneumococcus and three strains of streptococci. Journal of Experimental Medicine 99, 247-259.

Catlin, B. W. (1970). Haemophilus influenzae in cultures of cerebrospinal fluid: non-encapsulated variants typable by immunofluorescence. American Journal of Diseases of Children 120, 203-210.

Catlin. B. W., Bendler, J. W., III \& Goodgal, S. H. (1972). The type b capsulation of Haemophilus influenzae: map location and size. Journal of General Microbiology 70, 411-422.

Crisel, R. M., BaKer, R. S. \& Dorman, D. E. (1975). Capsular polymer of Haemophilus influenzae, type b: characterisation of the capsular polymer of strain Eagan. Journal of Biological Chemistry 250, 49264930.

GoodGal, S. H. (1968). Transformation with Haemophilus influenzae. Methods in Enzymology 12B, 864 876.

Goodgal, S. H. (1982). DNA uptake in Haemophilus transformation. Annual Review of Genetics 16, 169192.

Gromkova, R. \& Goodgal, S. H. (1977). The role of restriction enzymes of Haemophilus in transformation and transfection. In Mechanisms in Recombination, pp. 209-215. Edited by R. F. Green. New York: Plenum Press.

Gromkova, R. \& GoOdGal, S. H. (1979). Transformation by plasmid and chromosomal DNA in Haemophilus parainfluenzae. Biochemical and Biophysical Research Communications 88, 1428-1431.

Gromkova, R. C., Rowj, P. B. \& KoORnhoF, H. J. (1989). Induction of competence in non-encapsulated and encapsulated strains of Haemophilus influenzae. Current Microbiology 19, 241-245.

Herriott, R. M., MeYers, E. M. \& Vogt, M. (1970). Defined nongrowth media for stage II development of competence in Haemophilus influenzae. Journal of Bacteriology 101, 517-524.

Hoiseth, S. K., Moxon, E. R. \& Silver, R. (1986). Genes involved in Haemophilus influenzae type $\mathrm{b}$ capsule expression are part of an 18-kilobase tandem duplication. Proceedings of the National Academy of Sciences of the United States of America 83, 11061110.

KAHN, M. E. \& SMITH, H. O. (1984). Haemophilus: a problem in membrane biology. Journal of Membrane Biology 81, 89-103.

Kahn, M., Concino. M., Gromkova, R. \& Goodgal,
S. H. (1979). DNA binding vesicles produced by competence deficient mutants of Haemophilus. Biochemical and Biophysical Research Communications 87, 764-772.

KaHN, M. E., BaranY, F. \& SMITH, H. (1983). Transformasomes: specialized membrane structures that protect DNA transformation. Proceedings of the National Academy of Sciences of the United States of America 80, 6927-6931.

KiliaN, M. (1976). A taxonomic study of the genus Haemophilus with the proposal of a new species. Journal of General Microbiology 93, 9-62.

Notani, K. N., Setlow, J. K., McCarthy, D. \& Clayton, N. L. (1981). Transformation of Haemophilus influenzae by plasmid RSF 0885 . Journal of Bacteriology 86, 392-400.

O'Callaghan, C. H., Morris, A., Kirby, S. M. \& SHINGLER, A. H. (1972). Novel method for detection of $\beta$-lactamases by using a chromogenic cephalosporin substrate. Antimicrobial Agents and Chemotherapy 1, 283-288.

PitTman, M. (1931). Variation and type specificity in the bacterial species Haemophilus influenzae. Journal of Experimental Medicine 53, 471-492.

SMITH, H. O. \& DANNER, D. B. (1981). Genetic transformation. Annual Review of Biochemistry 50, 41-68.

STUY, J. H. (1979). Plasmid transfer in Haemophilus influenzae. Journal of Bacteriology 139, 520-525.

Thornsberry, C., ANhalt, J., Barry, A. L., Cotton, J. L., Gerlach, E. H., Jones, R. N., Moellering, R. C. \& Norton, R. A. (1985). National Committee for Clinical laboratory standards. Methods for dilution antimicrobial susceptibility tests for bacteria that grow aerobically. Approved standard. NCCLS publication M7-A. Vilanova, Pennsylvania: NCCLS.

Tolan, R. W., Munson, R. S. \& Granoff, D. M. (1986). Lipopolysaccharide gel profiles in Haemophilus influenzae type $\mathrm{b}$ are not stable epidemiologicalmarkers. Journal of Clinical Microbiology 24, 223227.

TURK, D. C. (1981). Clinical importance of Haemophilus influenzae. In Haemophilus influenzae, Epidemiology, Immunology and Prevention of Disease, pp. 3-9. Edited by S. H. Sell \& P. F. Wright. New York: Elsevier Biochemical.

Yother, J., De DANIEL, L. S. \& BRILES, D. E. (1986) Transformation of encapsulated Streptococcus pneumoniae. Journal of Bacteriology 168, 1463-1465.

ZAMENHOFF, S., Leidy, G., FitzGerald, P. L., Alexander, H. E. \& Chargaff, E. (1963). Polyribophosphate, the type specific substance of Haemophilus influenzae type b. Journal of Biological Chemistry 203, 696-704. 